\title{
Discussão sobre as Tecnologias de Acompanhamento e Avaliação da Aprendizagem no Blended Learning
}

\author{
Rosângela Saraiva Carvalho ${ }^{1,3}$, Ivanildo José de Melo Filho, ${ }^{1,2,3}$, Ana Luiza de Souza \\ Rolim $^{1,2,3}$, Alex Sandro Gomes ${ }^{1,3}$ \\ ${ }^{1}$ Centro de Informática - Universidade Federal de Pernambuco (UFPE) \\ ${ }^{2}$ Instituto Federal de Pernambuco - Campus Belo Jardim (IFPE) \\ Av. Sebastião Rodrigues da Costa, S/N - CEP: 55155-730 - Belo Jardim - PE - Brazil \\ ${ }^{3}$ Grupo de Pesquisa Ciências Cognitivas e Tecnologia Educacional (CCTE) \\ Caixa Postal 7.851 - 54.740-540 - Recife - PE - Brazil \\ rsc5@cin.ufpe.br; ivanildo.melo@belojardim.ifpe.edu.br; \{alsr, asg\} \\ ecin.ufpe.br
}

\begin{abstract}
This article presents the conclusion of the review of literature on the monitoring of individual student in the teaching modality "blended learning", which indicates that in despite of the existence of various assessment tools and monitoring there is a gap for the communication between the teacher-student in respect to social regulation and individual monitoring. Thus, we propose the creation of a computational tool that enhances communication and supports the assessment in virtual learning environment. Importantly, it is expected that the proposed tool can assist the teacher in reflection of their practice, in the search for comprehensive training and to overcome the difficulties of their students and consequent successful learning.
\end{abstract}

Resumo. Este artigo apresenta uma pesquisa em andamento acerca do acompanhamento individual do discente na modalidade "blended learning". A revisão da literatura indica que apesar da existência de diversas ferramentas de avaliação e acompanhamento do discente, observa-se uma lacuna quanto à comunicação entre docente-discente, no que tange à regulação social e ao acompanhamento individual. Assim, propõe-se a criação de uma ferramenta computacional que valorize a comunicação $e$ apoie a avaliação em ambiente virtual da aprendizagem. Espera-se que esta auxilie o docente, na reflexão de sua prática, na busca pela formação integral e na superação das dificuldades dos discentes.

\section{Introdução}

Desde que o ensino online começou a se tornar realidade, os educadores compartilham o desafio de como aplicar a tecnologia web no ensino, para a melhoria da aprendizagem [Alves; Guimarães; Oliveira e Rettori 2004]. Sendo assim, muitas pesquisas foram realizadas no intuito de investigar a eficácia das modalidades de ensino, e sugerem a modalidade blended learning ou b-lerning como uma alternativa eficaz para o processo de ensino e aprendizagem [Mohammad 2009] e [Tulaboev 2013].

Essa modalidade combina as melhores práticas do ensino tradicional e do $e$ Lerning, buscando compensar os pontos fracos de cada uma dessas modalidades de 
ensino, com vistas a promover uma aprendizagem onde o discente torne-se ativo e autônomo. $\mathrm{O}$ ensino tradicional possui caráter cumulativo, sendo o docente o detentor do saber e o discente receptor passivo das informações [Leão, 1999]. Por outro lado, [Clarck; Mayer 2011, p. 8] definem o e-Lerning como instrução entregue em um dispositivo digital, como um computador ou dispositivo móvel que se destina a apoiar a aprendizagem.

Dentre as características do blended learning, vale ressaltar: a maior flexibilidade das aulas e o aumento da interação e contato entre os discentes e o docente, bem como, entre os discentes. E também uma maior participação do discente introvertido, que com dificuldades de participar presencialmente, o faz de forma online. Porém, persiste a dificuldade de acompanhar individualmente o discente e as dificuldades de comunicação entre docente e discente, presentes em qualquer modalidade de ensino [Mohammad 2009].

Nesse cenário de mudanças de paradigma, em que os docentes necessitam adquirir novas habilidades de ensino, de modo a atender as características e usufruir dos benefícios e melhores práticas do b-lerning, a tecnologia tem sido incorporada ao ambiente de ensino e aprendizagem praticamente em todos os países.

Hoje, no Brasil, a maioria das escolas possui computadores, dessas, 89\% possuem acesso à internet, e esse número vem aumentando ano após ano segundo dados do IBGE - Instituto Brasileiro de Geografia e Estatística. Essa nova dinâmica requer uma escola mais ágil e adaptativa às necessidades e expectativas vigentes. Nesse contexto, segundo [Childress 2014], o centro da mudança para o ensino personalizado nas escolas está nas mãos dos docentes, que podem planejar aulas onde as experiências dos discentes são adaptadas às suas necessidades, habilidades e interesses individuais. Conteúdos e ferramentas dão suporte ao b-learning como recursos valiosos para alcançar esse objetivo.

Assim, a percepção das necessidades de mudanças na educação, diante das exigências da sociedade do conhecimento - a sociedade do conhecimento tem por base o capital humano ou intelectual [Lucci 2008] - impacta na conscientização do docente que, assumindo sua real importância e responsabilidade, torna-se crítico e exigente quanto à tecnologia que o auxilie no processo de ensino e aprendizagem.

Conforme [Bill \& Melinda Gates Foundation 2014], os docentes apontam que as tecnologias contribuem no diagnóstico da aprendizagem de cada discente, possibilitando que as lições sejam adaptadas de forma a atender as demandas individuais. Por essa razão, torna-se relevante o desenvolvimento de ferramentas capazes de auxiliar o docente no processo de acompanhamento individual do discente e, consequentemente, na reflexão da sua prática. O que pode melhorar os resultados de aprendizagem esperados, conforme contrato didático.

Em decorrência do exposto, há mais de três décadas, diversas pesquisas têm sido realizadas com vistas a integrar a tecnologia à sala de aula de forma expressiva, no ensejo de contribuir com o processo de ensino e aprendizagem. Muito tem sido discutido pelos educadores e inúmeras estratégias de integração têm sido recomendadas [Ertmer; Ottenbreit-Leftwich; Sadik; Sendurur; Sendurur 2012]. O debate em questão ultrapassa o simples uso de sistemas de gestão acadêmica, sistemas de gestão da aprendizagem ou de recursos tecnológicos que reproduzem a prática tradicional de ensino. A questão atual volta-se para como a tecnologia pode auxiliar o docente na 
formação do discente de forma a atender as necessidades da sociedade vigente [Carvalho 2010].

Neste sentido faz-se necessário garantir o desenvolvimento de conhecimentos, habilidades e atitudes para o exercício de todo e qualquer tipo de trabalho, mas também preparar o jovem para enfrentar os problemas cotidianos, bem como, para aprender contínua e autonomamente, de modo a promover o aperfeiçoamento dos valores humanos e das relações pessoais e comunitárias [Delois; Al Mufti; Amagi; Carneiro; Chung; Geremec; Gorham; Kornhauser; Manley; Quero; Savané; Singh; Stavenhagen; Suhr; Nazhao 2010].

Sendo assim, [Delois et al. 2010] sugerem que a educação precisa se adequar para formar indivíduos com habilidades e competências que ultrapassem as habilidades cognitivas, de modo a atender o mercado de trabalho contemporâneo. Porém, observa-se a ausência de ferramentas que auxiliem o docente na tarefa de acompanhamento e verificação do aprendizado das habilidades exigidas pelo mercado de trabalho.

Considerado o panorama até aqui descrito e admitindo a eficácia da modalidade blended learning afirmada por [Mohammad 2009] e [Tulaboev 2013], observam-se, algumas questões que precisam ser tratadas quando da adoção do blended learning. Dentre elas, pode-se citar o método de avaliação que de forma geral, atribui peso maior aos exames presenciais em detrimento de qualquer outra forma de avaliação. Acrescente-se a isso, o modelo de acompanhamento do discente que não propicia um canal simples e eficiente de comunicação entre docente-discente que auxilie o discente a superar suas dificuldades e ao docente rever sua prática. Tal comportamento tão presente em nossa realidade suscita o desafio de buscar novas práticas que contribuam com a formação integral do discente, o que leva a crer que o dilema não está mais em criar novas ferramentas de avaliação do processo de ensino e aprendizagem, mas, sim na criação de instrumentos de acompanhamento individual e avaliação adequados.

Assim, o problema tratado nesta pesquisa refere-se à dificuldade de o docente realizar o acompanhamento individual do discente e seu impacto nos fenômenos de ensino e aprendizagem. Entre os aspectos que envolvem o acompanhamento do discente, ressalte-se a importância da comunicação, uma vez que há indícios de que a relação docente-discente mediada por uma comunicação objetiva, clara, motivadora e que valorize a auto-estima pode estimular o discente em seu processo de aprendizagem [Wentzel 2012]. Deste modo, a comunicação assume papel fundamental no processo de ensino e aprendizagem, podendo auxiliar o docente a acompanhar e avaliar para prover feedback personalizado a todos os discentes, contribuindo para o aprimoramento do aprendizado. Vale lembrar que os processos: regulação e feedback, são vistos como muito importantes para a prática de avaliação, pelos investigadores da tradição francófona e anglo-saxônica, respectivamente, conforme [Black; William 2009].

Visto o exposto, a questão central é: Como uma ferramenta computacional que apoie a regulação em AVA - por meio da avaliação formativa e somativa - pode melhorar o processo de acompanhamento individual e a comunicação na modalidade blended learning. E, deste modo, proporcionar o desenvolvimento autônomo do discente e a melhoria da aprendizagem. 


\section{O Acompanhamento do Discente em Ambiente Virtual da Aprendizagem}

Ao longo da história da educação, o desempenho do discente vem sendo medido por meio da avaliação, contudo, considerando o contexto escolar atual, em que a tecnologia está presente na prática pedagógica, e mediante as exigências de adequação da escola às necessidades da sociedade vigente, torna-se fundamental desenvolver novos mecanismos que além de avaliar, acompanhem o desenvolvimento do discente.

No contexto supracitado, impende destacar que esta pesquisa respalda-se nos novos "paradigmas pedagógicos", os quais discutem o paradigma do docente reflexivo e o uso da tecnologia voltado para educação, não como um fim, mas como um meio. De acordo com [Lopes 2008, p. 1]: "Os professores são produtores ao elaborarem as propostas de cursos; conselheiros ao acompanharem os alunos; parceiros, ao construírem, junto com os especialistas em tecnologia, abordagens inovadoras de aprendizagens. Novos tempos, novas tecnologias e nova cultura com a presença de educadores".

Importa salientar as ideias trabalhadas por [Perrenoud 1999], para quem a avaliação objetiva ajudar o discente a aprender e, o docente a ensinar. Essa visão da avaliação como instrumento colaborador do desenvolvimento da relação docentediscente, baseia-se numa abordagem de avaliação que possibilita, ao discente, o controle e acompanhamento do seu processo de aprendizagem, e, ao docente, realizar o seu trabalho com qualidade, acompanhando o desempenho dos discentes ao longo da disciplina, e assim, ser capaz de refletir e aprimorar sua prática.

Assim, fica evidente que o docente precisa estar constantemente atento ao desempenho e evolução individual de seus discentes, de forma a contribuir com a superação das dificuldades e com a melhoria da aprendizagem. Deste modo, a avaliação, quando bem planejada, torna-se instrumento facilitador da reflexão docente que possibilita a melhoria da qualidade do ensino. Este trabalho considera que o docente deve acompanhar o discente também com o auxílio da tecnologia que pode melhorar a comunicação e a aprendizagem na modalidade "blended learning" [Motschnig-Pitrik; Standl 2013].

\section{Tecnologias de Acompanhamento e Avaliação da Aprendizagem}

O uso das tecnologias educacionais na sala de aula, desde o lápis até os recursos de TIC - Tecnologia da Informação e Comunicação - na prática docente têm sido objeto de estudo e pesquisa desde os primórdios da educação.

Nesse sentido, surgem os Ambientes Virtuais da Aprendizagem - AVA, cujo principal foco são as funcionalidades de gerenciamento e organização de conteúdo, e avaliação. Contudo, funcionalidades de ordem administrativa vêm sendo incorporadas ao ambiente, de modo a auxiliar no processo de acompanhamento e avaliação do discente. De forma geral, dentre as funcionalidade presentes nesse tipo de ambiente podem ser citadas: gerenciamento do conteúdo, registro da frequência, produção do discente, data e hora de acessos ao ambiente, bem como, data e hora de acessos as demais funcionalidades e ferramentas presentes no ambiente. Bem como, acesso a dados cadastrais, resultados das avaliações, calendário das atividades, prazos de atividades solicitadas, e, as mensagens trocadas entre os discentes, docente e tutores de um curso. 
É fato que há uma preocupação genuína em adequar e utilizar os novos recursos tecnológicos de forma eficaz em favor do ensino. Afinal, os novos meios de comunicação e as mais variadas mídias desafiam os que fazem a educação a inserir-se no contexto tecnológico atual, de forma a prover educação formal ou informal de qualidade que desperte o interesse dos aprendizes em meio a tantos estímulos tecnológicos e de comunicação. Dessa forma, não se pode negar que o desenvolvimento tecnológico impactou, e, continua impactando na Educação, bem como nas mais diversas áreas de conhecimento humano. [Milrad; Wong; Sharples; Hwang; Looi; Ogata 2013, p.98] ressaltam que: "O rápido desenvolvimento destas tecnologias combinadas com o acesso a conteúdo em diversos contextos permite os alunos experimentarem novas situações de aprendizagem para além da sala de aula. Aprendizagem Cross-contextual pode permitir uma experiência de aprendizagem contínua através de diferentes contextos, como casa-escola ou local de trabalhofaculdade" (nossa tradução).

Nesse cenário, diversas pesquisas vêm sendo realizadas e muitas ferramentas têm sido criadas com o intuito de auxiliar o acompanhamento e avaliação do discente, por exemplo:

a) interROODA - foi desenvolvida com o intuito de auxiliar no processo de avaliação da aprendizagem a distância. Foi modelada de forma a possibilitar a visualização das interações que ocorrem no ambiente virtual de aprendizagem ROODA. Conforme [Bassani; Behar 2006], nessa ferramenta, a avaliação da aprendizagem no plano individual centra-se nas ações e resultados do sujeito que está sendo avaliado. E, o conhecimento é uma construção individual que decorre da interação do sujeito com o seu meio. Por sua vez, o meio se constitui a partir da interação entre sujeitos, objetos e regras.

[Bassani; Behar 2006] relata que a avaliação da aprendizagem em AVA, compreende: a) avaliação por meio de testes online; b) avaliação da produção individual dos estudantes; e c) analise das interações entre alunos, a partir de mensagens postadas/trocadas por meio das diversas ferramentas de comunicação. Contudo, ressalta a preocupação da avaliação ser limitada a tais aspectos, e propõe que a avaliação vá além dos testes online, que se limitam ao âmbito individual, e sugere que se observe, também, o âmbito das interações coletivas, considerando aspectos quantitativos e qualitativos.

b) SeeAll - "um sistema interativo de autoria baseado em competências, com a finalidade de apoiar o planejamento do professor e acompanhar a aprendizagem individual dos alunos" [Venancio; Lopes 2012, p.2]. Nessa ferramenta, os usuários ao se cadastrarem, o sistema se encarrega de organizar e armazenar os registros, que podem ser relacionados aos seguintes aspectos: As Habilidades que são descritas pelos docentes e estão relacionadas às competências e às atitudes pretendidas. As Atitudes que estão associadas ao como agir em situações diferenciadas do cotidiano. As Vivências de Aprendizagem que compreendem as atividades, pesquisas, visitas, jogos, entre outros; e, por fim, as Competências que estão relacionadas ao desempenho do discente no sentido de que o seu conhecimento foi construído, ou pode está em desenvolvimento ou ainda não foi construído. 
Os autores [Venancio; Lopes 2012] acreditam que o discente deve ser acompanhado a qualquer tempo e espaço, no progresso de suas habilidades específicas para o desenvolvimento de competências, por meio das vivências de aprendizagem e das atitudes que elas acarretam. E que se faz necessário a existência de ferramentas que contribuam para o planejamento e acompanhamento da aprendizagem.

c) GENOME - "uma ferramenta elaborada com fins de avaliação na ótica da participação virtual e gerenciamento de notas para o ambiente virtual MOODLE utilizado pelo Instituto Metrópole Digital da Universidade Federal do Rio Grande do Norte (UFRN). Esta ferramenta surgiu da necessidade de um padrão avaliativo da participação dos alunos, de forma a estimular a interação entre alunos e tutores e quantificar esta participação" [Gomes; Oliveira; Medeiros 2012, p.1].

Para os autores [Gomes; Oliveira; Medeiros 2012], a participação mais ativa no AVA é um requisito desejável, que pode aumentar o interesse do discente, e, em consequência, melhorar os seus resultados no curso. Deste modo, acreditam que o estabelecimento de mecanismos de avaliação que contemplem a participação online é deveras importante para a compreensão do processo de aprendizagem na construção do conhecimento.

Vale ressaltar que independente de qual seja a tecnologia direcionada ao acompanhamento e avaliação da aprendizagem, [Milrad et al. 2013] ressaltam que esta deve ser capaz de proporcionar ao discente a capacidade de explorar a aprendizagem contínua, de ir além da execução das tarefas solicitadas pelos docentes, bem como, a capacidade de autorregular sua aprendizagem. Que os discentes sejam capazes de aproveitar as inúmeras possibilidades de aprendizagem, não se limitando as metas estabelecidas pelos docentes, ou mesmo pelos recursos disponíveis. Quanto ao docente, que o possibilite refletir e rever sua prática continuamente, além de auxiliá-lo no acompanhamento individual e avaliação do discente.

Sendo assim, apesar dos esforços na concepção de ferramentas que auxiliem o acompanhamento e avaliação do discente, a exemplo das ferramentas supracitadas [Bassani; Behar 2006]; [Venancio; Lopes 2012]; [Gomes; Oliveira; Medeiros 2012]. Observa-se uma lacuna quanto à comunicação entre docente-discente no que tange a regulação, ao acompanhamento individual e a avaliação da aprendizagem. Faz-se necessário, portanto, a existência de um mecanismo capaz de aumentar as ações de comunicação entre docente-discente, que provenha um feedback efetivo e estimule a regulação.

Porém, o acompanhamento do discente nas ferramentas computacionais aqui apresentadas não oportuniza uma comunicação individual clara, continua e próxima entre docente e discente - que possibilite a superação das limitações dos alunos ao longo do processo de ensino e aprendizagem.

\section{A Proposta}

Conforme [Wentzel 2012], há um consenso crescente de que a natureza e a qualidade da relação dos discentes com seus docentes desempenham um papel fundamental e central na motivação e engajamento dos discentes para o aprendizado. Docentes eficazes são geralmente descritos como aqueles que desenvolvem com seus discentes relações emocionalmente próximas, seguras e de confiança, capazes de fornecer ajuda 
instrumental e promover o senso de comunidade e cuidados nas salas de aula. Neste sentido, o autor supracitado defende que a melhoria da qualidade do relacionamento entre docente e discente, intermediada pela atenção aos processos de comunicação, apoia a motivação e o desenvolvimento dos discentes em direção aos resultados sociais e acadêmicos pretendidos.

Observa-se, neste contexto, que muito tem sido discutido acerca de como incentivar o discente a participar ativamente do processo de regulação social, porém, inexiste consenso dos teóricos sobre a metodologia a ser adotada. Tal desafio reflete a importância da comunicação docente-discente para o desenvolvimento das competências não cognitivas e acadêmicas dos discentes. Segundo [Wentzel 2012], os discentes valorizam e, consequentemente, buscam alcançar os objetivos acadêmicos e sociais demandados pelos docentes, quando percebem suas relações e interações e quando os objetivos e expectativas são bem definidos, oportunidade em que se torna imprescindível o auxílio emocional e intelectual do docente.

Vale lembrar que conforme [Michinov; Brunot; Le Bohec; Juhel; Delaval 2010]: a regulação social ou corregulação geralmente é usada para explicar o fenômeno da participação em atividades de aprendizagem, sua dinâmica e natureza relacional. Os processos de regulação social tais como: negociação, confronto e exteriorização de ideias, explicação e questionamentos podem ser observados por meio da interação (comunicação).

Esta pesquisa considera as hipóteses: (a) $\mathrm{h}_{1}$ : a avaliação formativa/somativa apoiada por uma ferramenta computacional de acompanhamento do discente em AVA que valoriza e apoia a comunicação entre docente-discente - impacta na aprendizagem discente transformando o docente em agente de socialização que cria contextos interpessoais capazes de influenciar os níveis de qualidade, de motivação e envolvimento dos discentes [Meira 1998]; (b) $\mathrm{h}_{2}$ : a avaliação formativa/somativa apoiada por uma ferramenta computacional de acompanhamento do discente em AVA estimula a comunicação; (c) $h_{3}$ : a avaliação formativa/somativa apoiada por uma ferramenta computacional de acompanhamento do discente em AVA - estimula a autonomia.

Para ilustrar a tese supracitada, é importante compreender que a "regulação social" aqui tratada está relacionada ao "acompanhamento individual do discente" pelo docente; ciclo que compreende: a avaliação como instrumento de comunicação entre docente e discente, porque é capaz de gerar feedback para o discente, impactando diretamente no processo de ensino e aprendizagem, e de proporcionar a reflexão docente sobre sua prática, vide Figura 1. Desta forma, a comunicação assume papel importante no sucesso da relação docente-discente e, consequentemente, no desempenho de ambos.

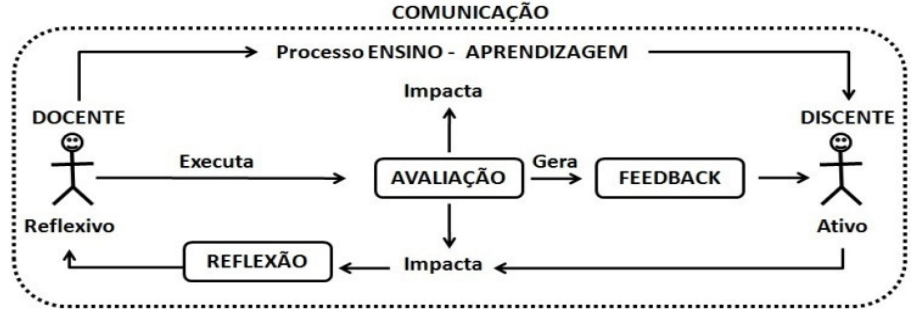

Figura 1. Ciclo do Acompanhamento Individual do Discente (Regulação Social). 
Considerando a dificuldade de o docente acompanhar individualmente, avaliar e se comunicar com o discente ao longo do processo de ensino e aprendizagem na modalidade blended learning, a presente pesquisa objetiva contextualizar que o "acompanhamento individual" depende do processo de comunicação.

Sendo assim, admitindo que a comunicação entre docente e discente não é inexistente, bem como, não se encontra em estado de excelência. E, que o acompanhamento individual do discente - inserido nos fenômenos de ensino e aprendizagem - que pode contribuir para a aprendizagem, é um processo difícil de ser realizado. Esta pesquisa tem por objetivo conceber uma ferramenta computacional de acompanhamento individual do discente que apoie a regulação em AVA, na modalidade blended learning.

\section{Considerações Finais}

Considerando o contexto supracitado, em que se faz mister o aprimoramento da comunicação entre docente-discente no âmbito das relações de ensino-aprendizagem, faz-se necessário encontrar meios para que o docente acompanhe o desenvolvimento do discente, de forma aproximada e contínua. Esta ação tem como objetivo garantir intervenções qualitativas ao longo do processo de ensino e aprendizagem e não apenas ao final do processo.

Esta pesquisa - em andamento - considera a avaliação somativa e formativa, mediada pela regulação e pelo feedback imediato, observados e aferidos por meio de uma ferramenta computacional de acompanhamento individual do discente, pelo docente, em AVA, na modalidade b-learning.

Nesse sentido, a concepção desse instrumento visa contribuir no preenchimento da lacuna existente nas ferramentas evidenciadas na literatura e aqui apresentadas, quanto ao acompanhamento individual do discente e da comunicação, aspectos importantes para a melhoria da aprendizagem; o que consequentemente demonstra sua relevância. Objetiva, portanto, aproximar docente e discente por meio de uma comunicação clara, próxima e contínua.

Sendo assim, considerando todos os aspectos aqui discutidos, busca facilitar o trabalho do professor diante de tantas tarefas a desempenhar, fornecendo informações que o auxilie a acompanhar e monitorar o discente buscando solucionar suas dificuldades ao longo do processo e não apenas ao final. Espera-se, portanto, que estimule a regulação social, influencie na melhora da comunicação e reduza a dificuldade das práticas avaliativas na modalidade blended learning. Com relação ao docente, espera-se que o auxilie na reflexão de sua prática, na busca pela formação integral e na superação das dificuldades de seus discentes. No que concerne aos discentes, a expectativa é de que contribua para os tornar autônomos, ativos e responsáveis pela sua aprendizagem, além de incentivar a busca do conhecimento que ultrapasse a execução das tarefas solicitadas.

Cumpre observar que a formação do discente deve ultrapassar os aspectos cognitivos, mediante as exigências da sociedade do conhecimento e do mercado de trabalho atual, sendo necessário, pois, formar integralmente o discente, considerando, também, aspectos não cognitivos como capacidade de gerir e resolver problemas, desenvolvimento da autonomia, aprendizado contínuo ao longo da vida. 
Por fim, como evidenciado, diversas questões podem ser abordadas, contudo, este trabalho delimita-se em verificar como a avaliação formativa e/ou somativa apoiada por um modelo de acompanhamento individual do discente em um ambiente virtual da aprendizagem, impacta na aprendizagem, estimula a comunicação e a autonomia do discente na modalidade blended learning.

\section{References}

ALVES, L., Guimarães, H., Oliveira, G., Rettori, A. (2004). "Ensino On-Line, jogos eletrônicos e RPG: Construindo novas lógicas”. In Conferência eLES (Vol. 4).

Bassani, Patrícia S; Behar, Patricia A “Análise das interações em ambientes virtuais de aprendizagem: uma possibilidade para avaliação da aprendizagem em EAD”, www.seer.ufrgs.br/renote/article/download/14044/7932.

Bill \& Melinda Gates Foundation (2014) "Teachers Know Best: What Educators Want from Digital Instruction Tools", http://collegeready.gatesfoundation.org/Portals/0/Documents/Teachers\%20Know\%2 0Best/Teachers\%20Know\%20Best.pdf.

Black, Paul and William, Dylan (2009) "Developing the theory of formative assessment". Educational Assessment, Evaluation and Accountability" (formerly: Journal of Personnel Evaluation in Education) February 2009, Volume 21, Issue 1, pp 5-31, http://link.springer.com/article/10.1007/s11092-008-9068-5\#.

Carvalho, Rosângela Saraiva (2010) "Sistemas de Gestão da Aprendizagem e Sistemas de Gestão Acadêmica: Avaliados pela Ótica do Docente". In: XXI Simpósio Brasileiro de Informática na Educação - SBIE 2010, 2010, João Pessoa. Anais do XXI Simpósio Brasileiro de Informática na Educação - SBIE 2010 - Concurso de Teses, Dissertações e TCCs.

Childress, Stacey (2014) "O que os educadores querem dos recursos tecnológicos", http://www.impatientoptimists.org/Posts/2014/04/Listen-to-Teachers--Thoughts-onDigital-Classroom-Tools.

Clarck, Ruth Colvin and Mayer, Richard E. (2011) "E-Learning and the science of instruction: proven guidelines for consumers and designers of multimedia learning" $3^{\text {o }}$ edition.

Delois, Jacques; Al Mufti, In'am; Amagi, Isao; Carneiro, Roberto; Chung, Fay; Geremec, Bronislaw; Gorham, William; Kornhauser, Aleksandra; Manley, Michel; Quero, Maristelo Padrón; Savané, Marie-Angélique Savané; Singh, Karan; Stavenhagen, Rodolfo; Suhr, Myong Won; Nazhao, Zhou (2010) "Educação - Um Tesouro a Descobrir" - Relatório para a UNESCO da Comissão Internacional sobre Educação para o Século XXI. Brasília: UNESCO no Brasil - Faber Castell, http://www.dominiopublico.gov.br/download/texto/ue000009.pdf.

Ertmer, Peggy A.; Ottenbreit-Leftwich, Anne T.; Sadik, Olgun; Sendurur, Emine; Sendurur, Polat (2012) "Teacher beliefs and technology integration practices: A critical relationship" Computers \& E Education, http://www.sciencedirect.com/science/article/pii/S0360131512000437. 
Gomes, A. V., Oliveira, D. S. da S., Medeiros, A. da C. (2012) "GENOME: uma ferramenta avaliativa de participação virtual”, http://www.brie.org/pub/index.php/wcbie/article/view/1943.

Leão, Denise M. M. (1999) "Paradigmas Contemporâneos de Educação: Escola Tradicional E Escola Construtivista". Cadernos de Pesquisa, ${ }^{\circ}{ }^{\circ} 107$, p. 187-206, julho/1999. http://www.scielo.br/pdf/cp/n107/n107a08.pdf

Lopes, Emilia Maria Martins (2008) "EAD: Mudança De Paradigmas Pedagógicos", http://www.administradores.com.br/artigos/carreira/ead-mudanca-de-paradigmaspedagogicos/23386/.

Lucci, E. A. (2008) “A era pós-industrial, a sociedade do conhecimento e a educação para o pensar" (notas de conferência para alunos e professores de ensino médio em diversos estados do Brasil), http://www.del.ufrj.br/ fmello/eraposindustrial.pdf.

Meira, Marisa Eugênia Melillo (1998). "Desenvolvimento e aprendizagem: reflexões sobre suas relações e implicações para a prática docente." Ciência \& Educação (Bauru) 5.2 (1998): 61-70.

Michinov, Nicolas; Brunot, Sophie; Le Bohec, Olivier; Juhel, Jacques and Delaval, Marine (2011) "Procrastination, participation, and performance in online learning environments", http://dx.doi.org/10.1016/j.compedu.2010.07.025.

Milrad, M.; Wong, L.-H.; Sharples, M.; Hwang, G.-J.; Looi, C.-K.; Ogata, H. (2013) "Seamless Learning: An International Perspective on Next Generation Technology Enhanced Learning", https://www.academia.edu/1947142/Seamless_Learning_An_International_Perspecti ve_on_Next_Generation_Technology_Enhanced_Learning.

Mohammad, Fouad (2009) "Blended Learning and the Virtual Learning Environment of Nottingham Trent University", http://ieeexplore.ieee.org/xpls/abs_all.jsp?arnumber=5395127\&tag=1.

Motschnig-Pitrik, Renate and Standl, Bernhard (2013) "Person-centered technology enhanced learning: Dimensions of added value", Computers in Human Behavior, http://dx.doi.org/10.1016/j.chb.2012.04.013.

Perrenoud, Philippe (1999) “Avaliação: da excelência à regulação das aprendizagens entre duas lógicas" Porto Alegre: ArtesMédicas, 1999, 183 p.

Tulaboev, Azamjon (2013) "Blended Learning Approach with Web 2.0 Tools". 3rd International Conference on Research and Innovation in Information Systems, http://ieeexplore.ieee.org/xpls/abs_all.jsp?arnumber=6716695\&tag=1.

Venancio, Valkiria; Lopes, Roseli De Deus (2012) "Competências e Avaliação Formativa em Sistema Interativo de Apoio a Aprendizagem e ao Planejamento voltado ao Ensino $\quad$ Fundamental", $\quad$ http://www.brie.org/pub/index.php/wcbie/article/view/1941.

Wentzel, Kathryn R. (2012) "Teacher-Student Relationships And Adolescent Competence At School”, http://link.springer.com/book/10.1007/978-94-6091-939-8. 